\title{
Gözlük Çerçevesi Üretimi İçin Otomatik Bir Sistem Geliştirme
}

\author{
Riza Ilhan ${ }^{1 *}$ \\ 1 İstanbul Aydın Üniversitesi, Mühendislik Fakültesi, Makina Mühendislik Bölümü, İstanbul, Türkiye (ORCID: 0000-0001-8975-9942) \\ (International Congress on Human-Computer Interaction, Optimization and Robotic Applications (HORA) 2021 - 11-13 June 2021)
}

(DOI: $10.31590 /$ ejosat.952696)

\begin{abstract}
ATIF/REFERENCE: Ilhan, R. (2021). Gözlük Çerçevesi Üretimi İçin Otomatik Bir Sistem Geliştirme. European Journal of Science and Technology, (26), 510-515.

\section{Özet}

Gözlüğün çerçevesi tipik olarak el aletleri kullanılarak adım adım yapılır. Bu süreç zaman alıcı, maliyetli ve hassas üretim için daha az doğru sonuçlar vermektedir. Bu makalede, gözlük çerçevesi üretmek için otomatik bir sistem sunulmuştur. Üretimde mekanize edilerek seri üretimde daha fazla ürün üretilmesi hedeflenmektedir. Yerli endüstriyel aparatların tasarımı ve üretimi çalışmaları bu amaç doğrultusunda sürdürülmektedir. Önerilen sistem robotik bir kol ve bir aparattan oluşmaktadır. Altı serbestlik derecesine (DOF) sahip robotik el kaynak için, apparat ise çerçeve parçalarını sabit bir konumda tutmak için kullanılmaktadır. Elde edilen sonuçlara göre, sistem kabul edilebilir performans göstermiş olup, mevcut üretim sistemleri ile ilgili eksiklikleri giderebilecek kapasiteye sahip sonuçlara ulaşılmıştır.
\end{abstract}

Anahtar Kelimeler: Robotik, Gözlük, Otomasyon

\section{Developing an Automated System for Production of Eyeglasses Frame}

\begin{abstract}
Eyeglass's frame typically is made step-by-step using hand tools. This process is time-consuming, costly, and less accurate for precise manufacturing. In this paper, an automated system to manufacture eyeglass frames is introduced. It is aimed to manufacture more products in mass production by mechanizing in production. The design and production of the domestic industrial apparatus are included in this purpose. The proposed system is composed of a robotic arm and an apparatus. The robotic hand having six degrees of freedom (DOF) is used for welding and the apparatus is used to hold frame parts in a fixed position. The system showed acceptable performance to remove shortcomings regarding current production system.
\end{abstract}

Keywords: Robotics, Glasses, Automation

\footnotetext{
* Sorumlu Yazar: Rıza İlhan İstanbul Aydın Üniversitesi, Mühendislik Fakültesi, Makina Mühendislik Bölümü, İstanbul, Türkiye, ORCID: 00000001-8975-9942, gilkhanisarkandi@,aydin.edu.tr
} 


\section{Giriş}

Gözlük ve güneş gözlüğü, gözlük pazarının büyük bir bölümünü oluşturmaktadır. $\mathrm{Bu}$ iki ürünün üretimi yüksek derecede ciddiyet ve doğruluk gerektirir. $\mathrm{Bu}$ nedenle, fabrikada kullanılan teknolojinin ve çalışanların önemi çok büyüktür. Model, gözlüklerin üretildiği hammaddeye bağlı olarak değişir. Gözlükler, üretim malzemelerine göre üç kategoride sınıflandırılır. Bunlar; metal gözlükler, plastik gözlükler ve bileşik gözlüklerdir. Malzeme olarak farklı uretim şekilleri mevcuttur (Speck et al., 2014; Goldstein, 1997). Malzeme belirlendikten sonra burun aralığı, lastik ebatları ve üretilecek model uzunluklarından sonra üretimi standart hale getirmek için aparatlar üretilir. $\mathrm{Bu}$ aparatlar çeşitli sorunlara sahiptir. Bunun yanı sıra yapılan gözlükler manual ve adım adım üretildikleri için düşük kaliteli ve uzun bir zamanda üretilmektedir.

$\mathrm{Bu}$ araştırma metal gözlükler ile ilgili yeni bir bakış açısı sunmaktadır. Çalışma kapsamında oluşturulan modelin alanında en çok üretilen modellerden olması ve birçok farklı alt modellere uygulama imkanı sağlaması nedeni ile üretimin büyük bir bölümüne uygulanabilir olan bu otomotik sitem geliştirilmiştir. Çeşitli modellerin kaynak işlemleri gerekli aparat ayarlama, robot ayarlama ve kontrol işlemlerinin yapılmasından sonra kullanılacaktır.

\section{Materyal ve Metot}

\subsection{Aparat Tasarımı}

Gözlükler genellikle çeşitli parçalardan oluşmaktadırlar. Bu parçalar birbirine kaynatılıp gözlüğün çerçevesini oluştururlar. Optik veya güneş gözlüklerinde olsun gözlüklerin çeşitli model ve şekilleri bulunmaktadır. Genellikle optik gözlükler temel beş parçadan oluşmaktadır. Araştırmamızın konusu olan 1157 model gözlük çerçevesi beş temel parça ile toplam olarak dokuz parçadan oluşmaktadır. Bu parçaları birbirine kaynatma adımları, Şekil 1'de gösterilmiştir. Şimdiki üretim işlemi dört aşamayla gerçekleştirilmektedir. Bu aşamalar ardı ardına yapılmaktadır. Her bir aşamanın üstüne parçaların sabitlendiği özel bir kalıbı vardır. Kaynak işlemi manuel olarak personel tarafindan gerçekleştirilmektedir. Dolayısıyla gözlüğün kalitesi ve üretim hızı personele dayanmaktadır. Şimdiki üretim metodunun en önemli dezavantajları a) Düşük kalite b) Üretim işleminin yavaş ve uzun süreli olması ve c) Eski ve ilkel olması gibi nedenler olarak düşünülebilir. Ayrıca üretimde kullanılan aparatların sorunları ve önerilen çözümleri aşağıdaki şekilde özetlenebilir:
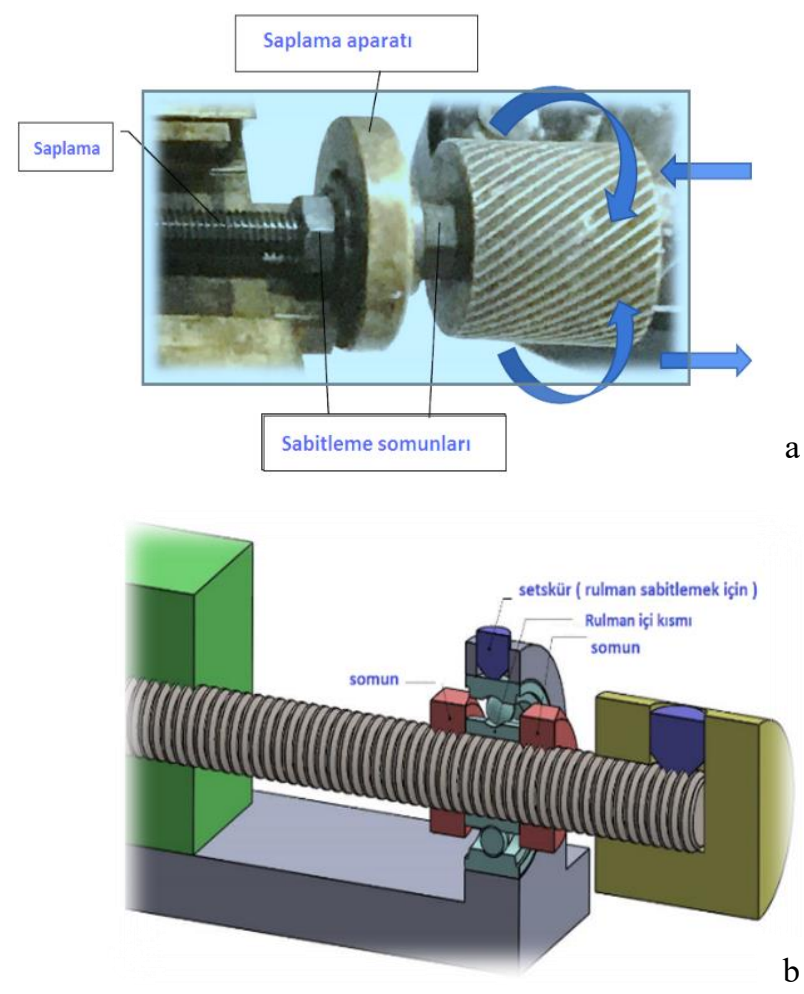

Şekil 2: Birinci sorun için önerilen çözüm. Bir rulman ve iki somun kullanılmıştır.

\subsubsection{Aparatın doğrusal hareketi}

Özellikle bu kalıbın sıkıntısı doğrusal eksenlere bağlı hareket eden bölümlerinde gözlenmektedir. Nedeni ise doğrusal eksenleri saplama yoluyla ayarlama yapılmasıdır. Şekil 2a da görüldüğü gibi saplama iki rondela ve iki somunla her iki tarafa bağlanmıştır. Bu iki somun saplama ile kaynaştırılmış olup saplamayı aparata bağlamaktadır. Ancak saplamanın serbest dönme alanı olması için somunlar tam sıkılmamalıdır. Somunlar tam sıkılmayacağı için saplamada doğrusal eksene paralel olarak boşluklar oluşacaktır. Bu boşluk ise kalıbın ayarlanmasındaki sorunun ana çekirdeğidir, çünkü doğrusal eksenlerde boşluklar oluştuğunda ayarlama kontrolü mümkün olmamaktadır. Saplama çok az sağa doğru daha sonra sola doğru döndürüldüğünde saplamaya bağlı eksenin hareket etmediği görülmektedir. Oysa eksen saplama döndürüldüğünde hareket etmelidir. Önerilen çözüm Şekil 2b de gösterilmektedir. Bu yöntemle bir rulman kullanılmıştır.
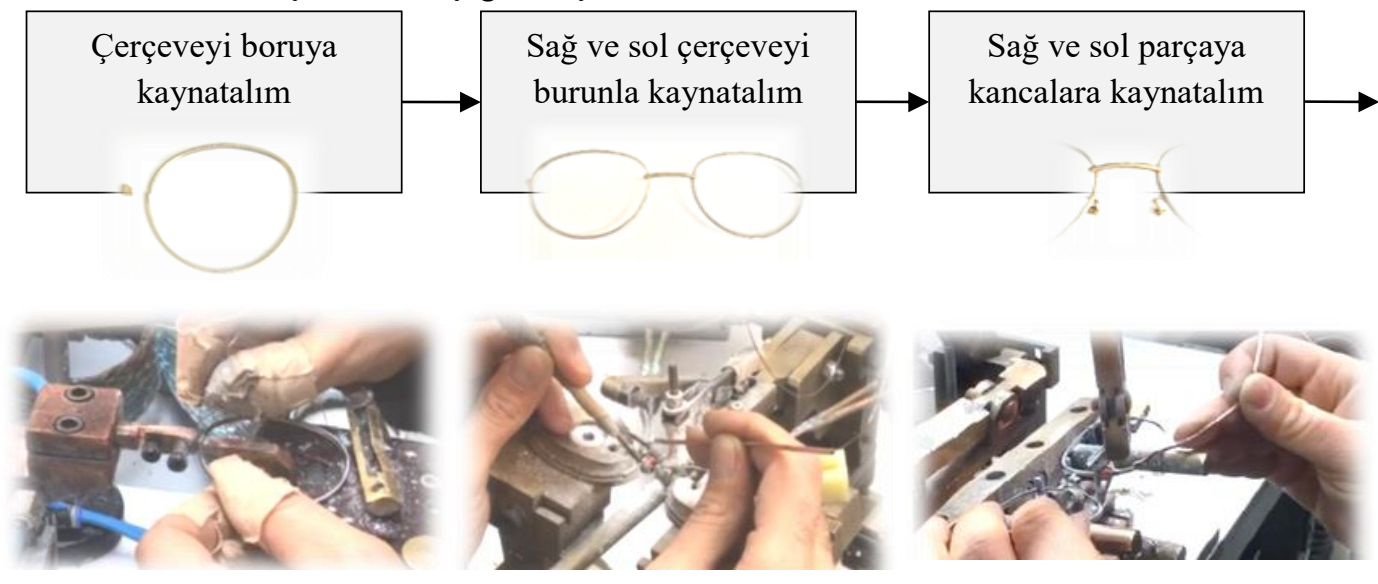

Sağ ve sol sap parçalarının kaynak işlemini yapalım

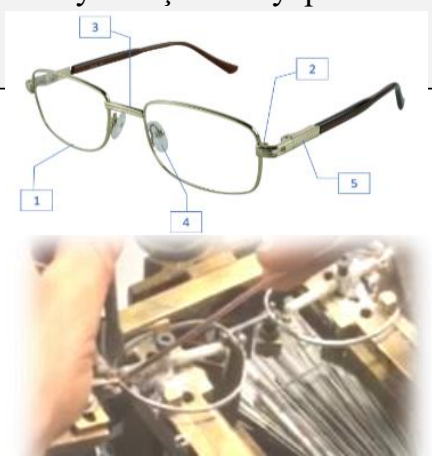

Şekil 1: 1157 gözlük çerçevesi, bileşenleri ve Gözlüğün ölüştürmasının adımları 
Rulmanın dış kısmı aparata sabitlenmiştir. İç kısmı ise iki somunla saplama sıkıştırılmıştır. Bu yöntemle saplama özgürce kendi ekseninde dönebilecek ve doğrusal hareketi engelleyebilecektir.

\subsubsection{Aparatın sabitlemesi}

Aparat ayarlandıktan sonra sabitleme işlemleri yapılırken sıkıntı yaşanmaktadır. $\mathrm{Bu}$ sorunun temel nedeni eksenlere sabitleştiren vidalardır. Çünkü aparatı ayarladıktan sonrası parçalarını sabitleştirme işlemi vidalarla eksenlere sabitleyerek gerçekleştirilmektedir. Ancak saplamanın hareket özgürlüğü ve bir önceki bölümde bahsedilen gibi bulunan boşluklar nedeniyle vidalar sıkıldığında eksende vida hareketine bağlı sağa doğru kaymalara neden olmaktadır. Şekil 3a eksenleri sabitleştiren vidaları göstermektedir. Önerilen çözüm Şekil $3 b$ de gösterilmektedir. $\mathrm{Bu}$ sorunun çözümü ise, kolayca saplamayı somun ile sabitleştirmektir. Böylece hiçbir kayma yaşanmadan eksen sabitleştirilecektir. Tabi bir önceki bölümde bahsettiğimiz eski aparata boşluklar nedeniyle somun yerleştirilememekteydi, ancak yeni tasarımda bütün boşluk sorunları çözülmüş olabilmektedir. Böylece saplamayı sabitleştirmekle eksen de sabitleştirilmiştir.

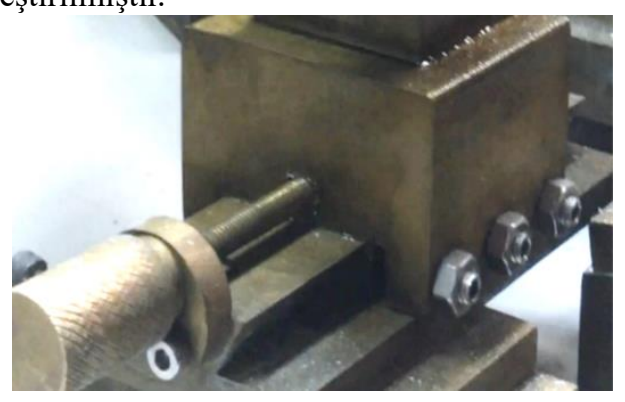

a

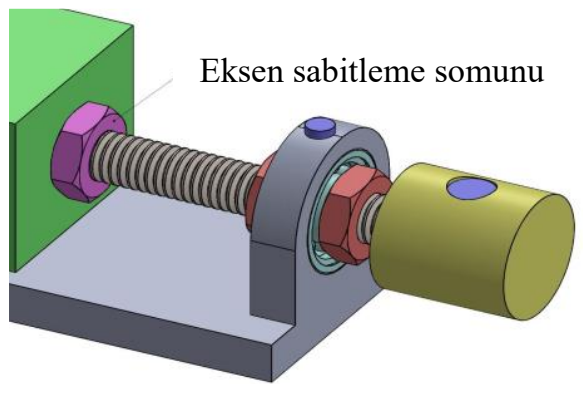

b

Şekil 3: İkinci sorun için önerilen çözüm.

\subsubsection{Aparatın bölümleri arasında oluşan kaymalar}

Zamanla aparatın bölümleri arasında kaymalar oluşur. $\mathrm{Bu}$ kaymalar aparatın ayarında değişikliğe neden olur. Bu nedenle bazı gözlükleri bu kalıbın üstüne sabitlemek mümkün değildir. Şekil 4a parçaların aralarında kanal olmadan nasıl yerleştirildiği gösteriyor. Burada görüldüğü gibi bu sorun kalıbı oluşturan hemen hemen bütün parçalarda bulunmaktadır çünkü bütün parçalar aralarında kanal olmadan birbirine bağlanmışlardır. Eksenlerin kayma sorununun çözülmesi amacıyla bu çalışmada, Şekil 4b'de görüldüğü gibi "ray ve araba" yöntemi kullanılarak yeni eksenler tasarlanmıştır. Aynı zamanda bir taraftan rayların diğer taraftan arabaların yerleştirileceği kanallar açılmıştır. $\mathrm{Bu}$ yöntemle, kırlangıç slaytları (dovetail slides), yüksek kalite olan lineer ray ve arabalar (linear guide rail) ile değiştirilerek sürtünme

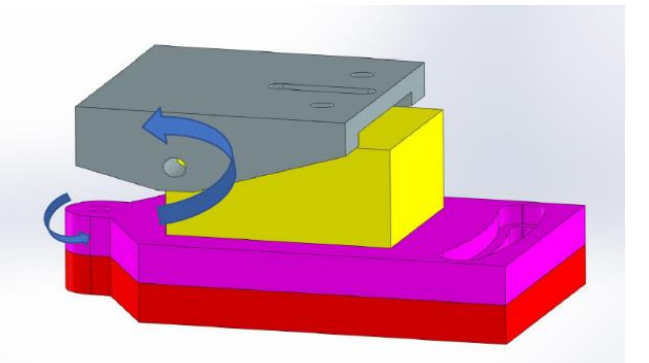

a

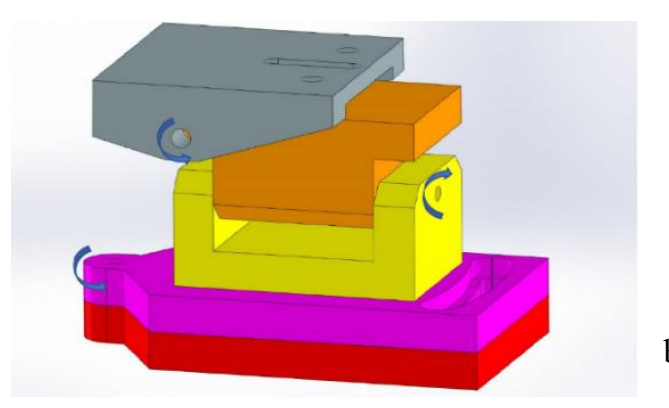

Şekil 4: Üçüncü sorun için önerilen çözüm.

engellenmiştir. Böylece, aparatın daha uzun ömürlü ve daha çok dakik olması mümkün olabilmektedir.

\subsubsection{Serbestlik derecesi}

Gözlüklerin kenar kısımlarına uygulanan kaynağın verimi serbestlik derecesi ile ilişkilendirilebilir. Düşük serbestlik derecelerinden ötürü bazı gözlüklerin kaynak kabileyetleri kısıtlamaktadır. Özellikle çoğu gözlükler altı serbestlik derecesi seviyeli olmaktadır. Sap gözlüğün çerçevesiyle bağlandığında sapın yerleştirilme kenarı son derece hassas kenarda olmaktadır. Bu nedenle kenarı sisteme aktarabilmek için kalıbın esnek olması gerektirmektedir. Ancak eski aparatta eksik dairesel eksenler bulunmaktadır. Şekil 5a eski aparatların dairesel eksenlerini göstermektedir. Bu sorunun çözülmesi için üçüncü dairesel eksen eklenerek yeni bir tasarım yapılmıştır. Şekil 5b'de görüldüğü gibi bu yeni tasarımla kalıbın ayarlaması bütün eksenlerle gerçekleştirilebilmektedir. Bu yöntemle, bazı gözlüklere özel yeni aparat üretimine ihtiyaç duyulmadan, üretilen bütün gözlüklerin
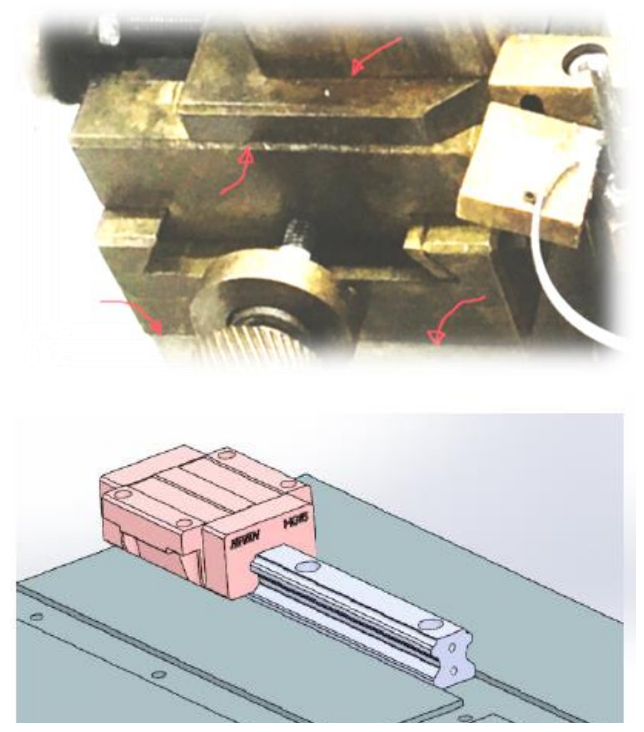

Şekil 5: Serbestlik derecesini artırmak için önerilen çözüm. 


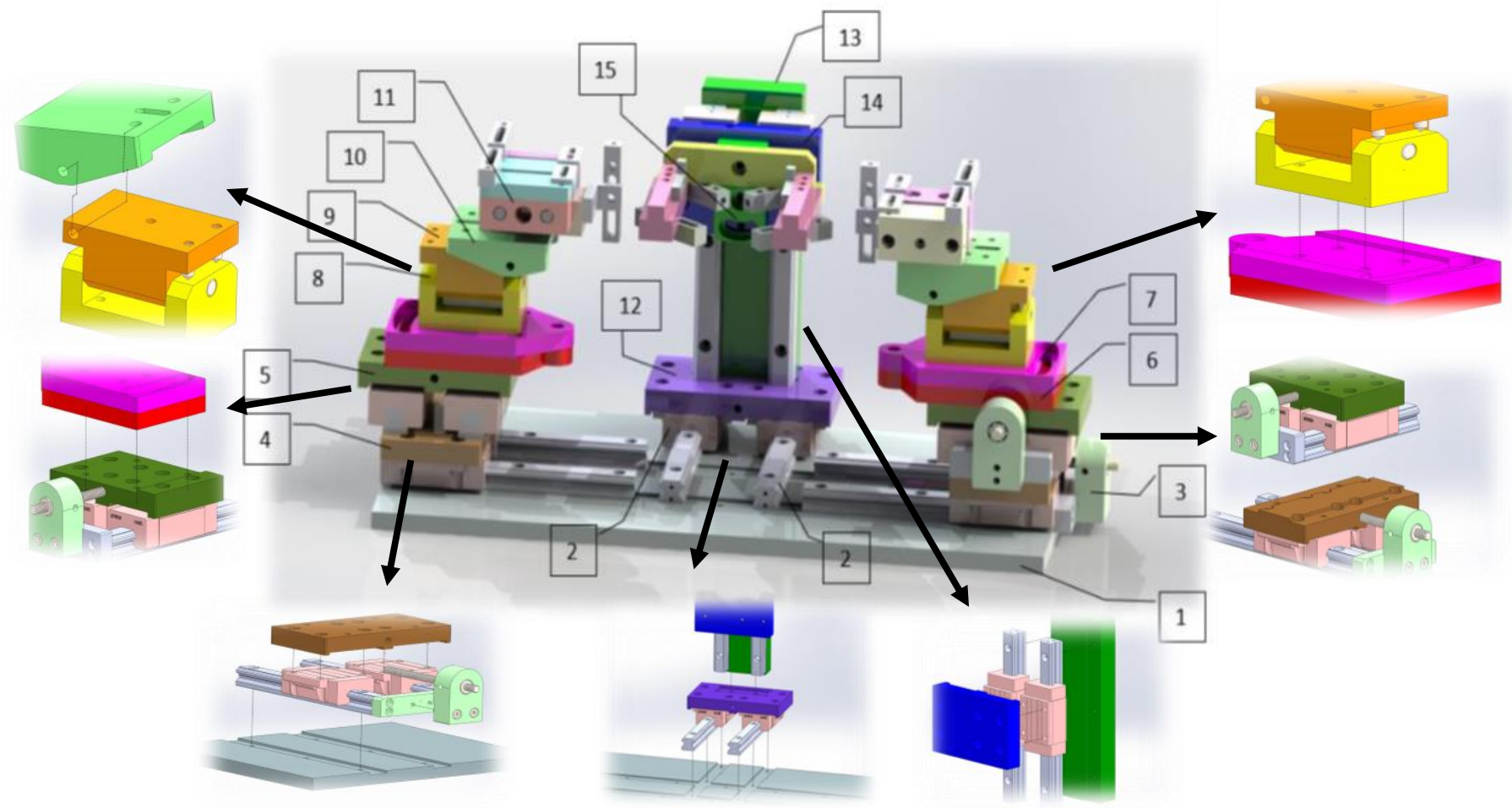

Şekil 6: Aparatın parçaları 1) Aparat alt parçası 2) Kızaklı ray araba sistemi (XX) 3) Saplamalı ayar seti 4) X ekseni arabast 5) $Y$ ekseni arabası 6) C Döner ekseni alt parçası 7) C Döner ekseni üst parçası 8) B Döner ekseni alt parçası 9) B Döner ekseni üst parçası

tutulabileceği tek bir aparat tasarlanabilir. Bu şekilde üretimin maliyeti düşecektir.

Önerilen çözümler toplandığında kalıbın son tasarımı Şekil 6 gibidir. $\mathrm{Bu}$ tasarımda parçalar arasında hiç boşluk yoktur. Yerleştirme kanallarından dolayı bütün parçalar doğru şekilde tam yerine yerleşebilmektedir. Sabitleme işlemi, istenilen ayarda hiçbir kayma veya değişim olmadan kalıbı basitçe somunla sabitleştirme imkânı verir. "Kırlangıç slaytları" yerine "lineer ray ve arabalar" sayesinde eksenler arasında sürtünme meydana gelmemekte ve sonuç olarak doğru ayarlamalar yapilabilmektedir.

Doğrusal X ekseni Şekil 6 de gösterildiği gibi "lineer ray ve arabalar" kullanılarak tasarlanmıştır. Bu yöntemle "kırlangıç slaytlar"'nda yaşanan sürtünme sorunları ortadan kalkmaktadır. Aynı zamanda ayarlamanın kontrolü daha kolay mümkün olabilmektedir. Bununla birlikte rayların ana plakada yerleştirileceği kanallar açılmıştır. Böylece tamamen tasarlandığı noktaya yerleştirilebilecek ve zamanla kayma riski olmayacaktır. Aynı zamanda rayları yerleştirmede aynı hedefle X ekseninin hareketli masasına yerleştirilecek olan arabanın kanalları da açılmıştır. Aparatta sağda ve solda doğrusal eksen X bulunduğu göz önünde bulundurulmalıdır.

Doğrusal Y ekseni X ekseninin üzerine yerleştirileceğinden, $\mathrm{Y}$ ekseninin raylarını $\mathrm{X}$ ekseninin arabasına dikey şekilde yerleştirmek gerekir. Rayların yerleştirileceği kanalları açma konusunda çözüm metodu uygulanarak, Şekil 6 da Y ekseninin ray kanallarını $X$ ekseninin üst yüzeyin de açıldığ gösterilmektedir. $\mathrm{Y}$ ekseninin hareketli alt yüzeyine arabanın yerleşeceği kanallar açılmıştır. Aparatta sağda ve solda Y doğrusal eksenleri bulunmaktadır.

Döner eksen A için tasarım da yerleşme ve dayanma yeri açılmıştır. Bu şekilde konum en ince şekilde belirlenebilecektir.
$\mathrm{Bu}$ yerleşme yeri $\mathrm{Y}$ ekseninin üst yüzeyin açılmıştır. $\mathrm{Bu}$ parçalardan sağda ve solda iki adet bulunmaktadır.

Döner eksen B, A ve B eksenlerini bağlayan parça eklemli olmalı ve iki eksene dikey şekilde yerleştirilmelidir. Bu şekilde aparat için altı farklı eksenli döner ek bir eksen şekillenecektir. Bu eksenle sapın çerçeveye yerleşme kenarına istinaden kalıbı ayarlamak mümkün olacaktır. Aynı zamanda aşağıdaki şekilde gösterildiği gibi ince kalibrasyon için eksenin iki tarafına vidalar eklendi. Parçalar sağ ve sol taraflar da görülmektedir.

C döner ekseni saplamalı ayar setini bağlayan parçaların yerleştime kanallarına konumlandırılmıştır. Böylece parçanın zamanla kayma ihtimali engellenmiş ve daha sabit yerleşmesi sağlanmıştır.

Doğrusal $\mathrm{Z}$ ekseni temel yapısı açısından $\mathrm{X}$ ve $\mathrm{Y}$ eksenleriyle benzerdir. Tasarım açısından $Z$ ekseni öncelikle dikey şekilde konumlandırılmıştır. Daha sonra eksene paralel olarak ray sistemi yerleştirilmiştir. Rayları sabitleştirmek için ray yerleştirme kanalları açılmıştır. Açılan ray yerleştirme kanalları ile araba sistemi $\mathrm{Z}$ ekseninde sabitlenmiştir.

Bazı gözlüklerin küçük bazı gözlüklerin büyük olması nedeniyle, aynı zamanda her defasında sağ - sol X eksenini ayarlamamak adına, $\mathrm{X}$ eksenine uyumlu $\mathrm{Z}$ ekseninin altına doğrusal yardımcı eksen yerleştirildi. $\mathrm{Bu}$ eksen kalibrasyon işleminde yardımcı olacaktır. Bazı durumlarda bu ekseni ayarlamak sağ ve sol X eksenini ayarlanmasını gerektirmeyecektir. Aynı zamanda tasarımı bir önceki doğrusal eksenin tasarımına benzemektedir. Aynı şekilde kaideye rayların yerleştirileceği kanallar açılacak, arabaların yerleştirileceği kanallar ise XX ekseninin alt masasında açılacaktır. Üst taraftan ise $\mathrm{Z}$ eksenini taşıyan dikey kaideye kanallar açılmıştır. 


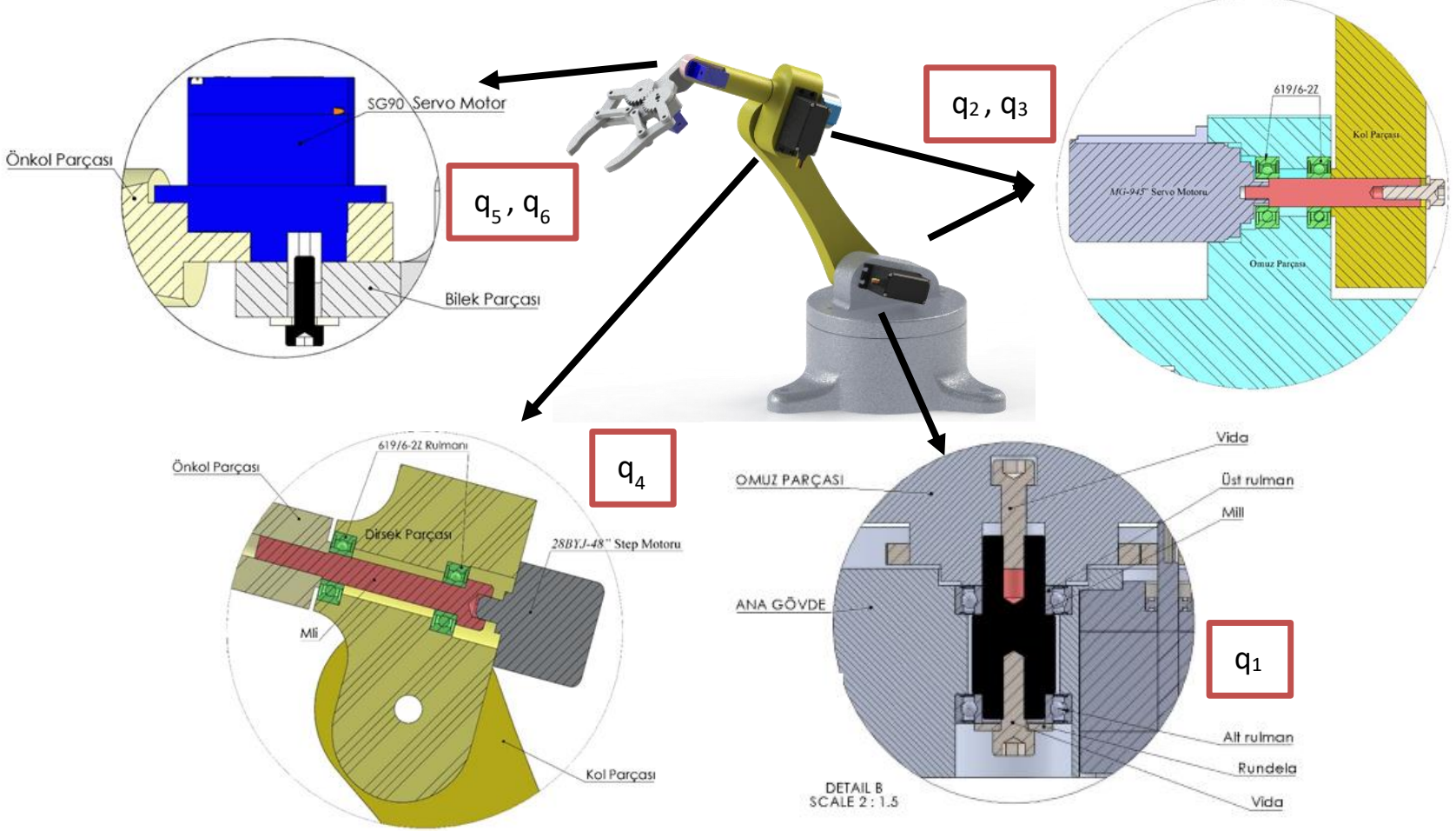

Şekil 7: Tasarlanan robot kolu altı dönel eklemden oluşmaktadır. Dönel eklem mekanizmasında hareket gücünü ve rijitliği sağlayan rulmanlar ve sabitleyici vidalar düşünülmüştür.

\subsection{Kaynak Robot Tasarımı}

Nokta kaynağı, en yaygın endüstriyel robot uygulamalarından biridir. Nokta kaynağı, temas noktalarında yüksek mukavemetli bir elektrik akımı geçirerek konsantre noktalarda iki metal parçası arasındaki füzyondur. Kaynak işlemi, iki metali bir araya getiren ve akımı temas noktasından geçiren bir tür iz ile gerçekleştirilir. Robot nokta kaynağından beklenilen özellikler bu şekildedir; a) Robot kolun lehim kaynak noktaları arasında özgürce hareket etmelidir b) İstenilen lehim kaynak açılarına ulaşması gerekiyor c) Gözlüğün açıları her tarafin altı seviyesine yüzeyine göre değişkenlik gösterdiği için gözlüğün iki tarafına göre altı seviyeye yüzeyine dayalı açılar olmalı. Buna istinaden altı serbestlik dereceli olan robot kolu seçilmiştir. Temas bölgesi otomatik olarak 1sıtılacaktır. Ardından robot lehim kaynak maddesini üstünde eritecektir. Şunu söylemek gerekir robot tasarımında 1sıtma telleri doğrudan gözlüklerin altına monte edilmektedir. Bunun anlamı lehim kaynak işleminin gözlüğün üst tarafında gerçekleşmesindendir. Dolayısıyla lehim kablosu kaynak teli ve bu kabloyu kontrol eden robotun hareket alanı üst tarafta olacaktır. Robot Şekil 7 de görülmektedir. Robotun genel tasarımı ve analizleri farklı kaynaklarda verilmiştir (Duymazlar, 2020; Havusoğlu, 2014; Iqbal et al., 2012; Özüdoğru, 2020; Nguyen et al., 2019; Sarialtın, 2017). Sadece robotun performans1 artmak için bazı adımlar atılmıştır. Birinci eklem q1 ana gövde ile omuz arasını bağlayan birinci eklemdir. $\mathrm{Bu}$ tasarımla eklemin merkezi duruşu, gücü ve sertliği korunmaktadır. Buna istinaden iletim için 61902 nolu rulman eklenmiştir. İkinci ve üçüncü eklemler aynı şekilde tasarlanmıştır. Bu iki eklem hareketi "MG945" servo motoruyla almaktadırlar. Eğilim direkt motorun eksenine bağlanacaktır. Eğilimin diğer tarafi ise bir sonraki parçaya bağlama vidasıyla bağlanacaktır. Kontrol devresi Arduino olup "Arduino mega” bordunu kullanılmıştır.
Kaynak işlemini gerçekleştirmek için robot gözlük çerçevesi kaynağının masasına monte edilmiştir. Daha sonra kaynağın yapılması gereken noktaları belirleyerek kaynak işlemi başlatılmıştır. Noktalar kartezyen kordinat sisteminde belirlenmiştir ve robot ileri kinematik denklemler üzerine uygulanmıştır. Birleştirilmiş sistem ve kaynak denemeleri Şekil 8 de gösterilmektedir.

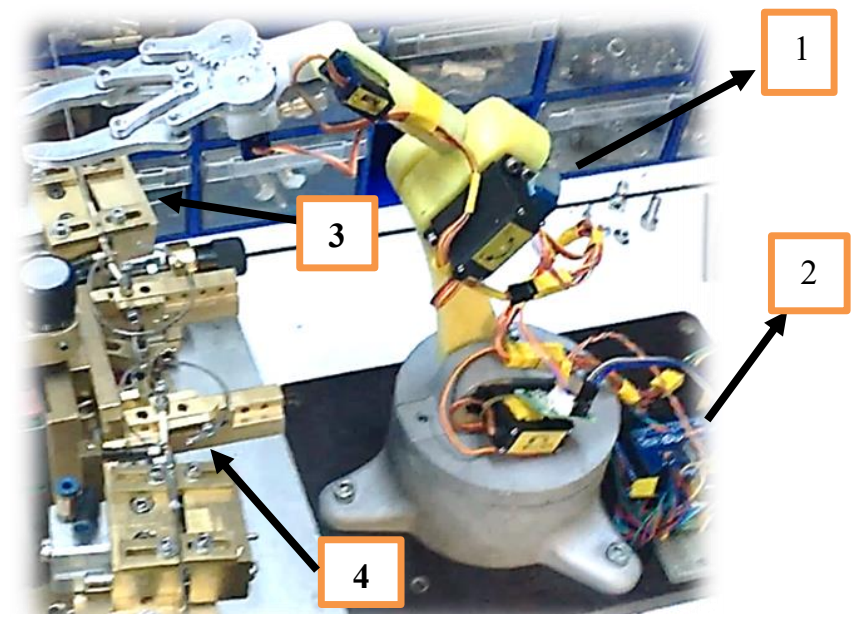

Şekil 8: Robot kolu ve aparatın birleşmiş hali. Gözlük aparatın üzerine monte edilmiş ve robot kolu kaynak işlemini yapmaktadır. 1)Robot kolu 2) Kontrol ünitesi 3) Aparat 4) Gözlük

\section{Sonuç}

$\mathrm{Bu}$ araştırmada gözlük üretimini kolaylaştıran bir sistem tasarlanmıştır. Sistem iki parçadan oluşmaktadır. İlk parça gözlüğü sabit tutmak için aparat ve ikinci parça kaynak yapmak için robot kol tasarlamaktır. Sonuçta tüm gözlük çeşitlerin üretimi 
için tek bir kalıbın tasarlanmasının mümkün olduğu sonucuna varılmışıır. Bu çalışmada, kalıbın ayarlama işlemi basitleştirilerek zaman kayb1 yok edilmiştir. Aparattan istenen performansı elde edebilmek için kalıbın hareket kabiliyetinin çift taraflı önüç serbestlik dereceli tasarlanmasına dikkat edilmiştir. Böyle bir gözlüğün bütün dereceleriyle en ince ve değişken kenarlarını kontrol edebilmek mümkün olmaktadır. Sağ ve sol olmak üzere her iki tarafın $\mathrm{X}$ ve $\mathrm{Y}$ ekseninde hareket özgürlüğü sağlanmıştır. Bununla birlikte $M_{z}$ ekseninde dikey dönme hareketi ve $M_{x}, M_{y}$ eksenlerinde ise yatay dönme hareketi sağlandığ görülebilmektedir. $\mathrm{Bu}$ hareket parçaları yerleştirme ve sabitlemenin bütün imkanlarını sunmaktadır. Tasarlamada eksen ve kaydırıcılara dayanarak, kalıbın hareket kalitesine zarar verilmeden ve sarsılmadan hareket etmesi sağlanmaktadır. Robot tasarımında altı serbestlik dereceli olan bir robot kolu seçilmiştir. Robot çalışma üzayında gözlügün tüm nokta kaynakları yapılabilmektedir. Noktalar manual olarak seçilmiş ve ileri kinematik denklemlere uygulanarak robotun üç işlevcisinin de seçilen noktalara yetişmesi mümkün kılınmıştır.

\section{5. Öneriler}

Önerilen sistem, mevcut gözlük üretim sisteminin performansını iyileştirir. Gelecekte, kaynak noktalarının konumunu algılayabilen ve aparatın kendisini buna göre ayarlayabildiği bir geri bildirim sisteminin oluşturulması düşünülmektedir. $\mathrm{Bu}$, görüntü işleme teknikleri kullanılarak gerçekleştirilecektir.

\section{Kaynakça}

Duymazlar, O. (2020). Design and application of a fast inverse kinematics algorithm for 6 dof open chain serial robots. EGE University, Izmir, Turkey

Goldstein, M. J. (1997). Eyeglasses (Household History Series). Carolrhoda Books.

Havusoğlu, H. (2014). Robot arm design, kinematic analysis and interactive control, Dokuz Eylül University, Izmir, Turkey

Iqbal, J., Islam, R. U., \& Khan, H. (2012). Modeling and analysis of a 6 DOF robotic arm manipulator. Canadian Journal on Electrical and Electronics Engineering. 3. 300-306.

Nguyen M.T., Yuan C., Huang J.H. (2019) Kinematic Analysis of A 6-DOF Robotic Arm. In: Uhl T. (eds) Advances in Mechanism and Machine Science. IFToMM WC 2019. Mechanisms and Machine Science, vol 73. Springer, Cham.

Özüdoğru, F. (2020). Target position joint angles of industrial robot arm model estimating by using constructive neural network and application of controlled trajectory, Tokat Gaziosmanpaşa University, Tokat, Turkey

Sarıaltın, E. (2017). 5-axis industrial robot arm, Istanbul Gelişim University, Istanbul, Turkey

Speck, A., Zelzer, B., Langenbucher, A., \& Eppig, T. (2014). Quality control of injection molded eyewear by non-contact deflectometry. Journal Of The European Optical SocietyRapid Publications, 9. 